\title{
SECOND-ORDER ANALYSIS OF 2-D STEEL FRAMES AT ELEVATED TEMPERATURES
}

\author{
J.Y.K. Chan ${ }^{1}$, S.S.H. Cho ${ }^{2}$ and F.G. Albermani ${ }^{1, *}$ \\ ${ }^{1}$ School of Civil Engineering, The University of Queensland, Australia \\ ${ }^{2}$ Department of Civil and Structural Engineering, The Hong Kong Polytechnic University, Hong Kong \\ *(Corresponding author: E-mail: f.albermani@uq.edu.au)
}

Received: 24 November 2010; Revised: 16 February 2011; Accepted: 25 February 2011

\begin{abstract}
At elevated temperatures, the stress-strain relationship of steel will be nonlinear. When one of the columns of a steel frame is subject to a local fire, the material properties of the column will deteriorate locally. Although the column is weakened, the steel frame will not collapse immediately if the frame is robust enough so that the excessive internal forces of the column can be redistributed by its connecting members. Structural design with robustness consideration can prevent a steel building under local fire from collapse. This paper is to propose a second-order analysis and design method for 2-D steel frames considering the nonlinear stress-strain relationship of the material under elevated temperatures. Results are found to be in line with the Eurocode 3 predicted failure loads.
\end{abstract}

Keywords: Steel, Column, Frame, Fire, Elevated temperature, Second-order analysis

\section{INTRODUCTION}

There is an increasing trend of constructing skyscrapers today because of the scarcity of lands and the rapid growth of population. Because of the huge amount of construction materials required to build a skyscraper, the construction materials are bound to be light-weight. Therefore, among the common construction materials, steel is most widely used due to its light weight and high strength. However, the height of the skyscraper and the huge amount of occupants it accommodates make the evacuation more difficult in case of fire. Steel is particularly vulnerable to high temperature. Its material properties start to deteriorate at temperature as low as $100^{\circ} \mathrm{C}$. At $600^{\circ} \mathrm{C}$ its design strength is almost reduced to half and at $1200^{\circ} \mathrm{C}$ it will lose all its strength. Although intense local fire weakens structural member rapidly, progressive collapse can be avoided if the structure is designed properly so that it is robust to the local failure. For instance, redundant members can provide an alternative load path in case of fire. Therefore, it is important to study the structural behaviour of steel structures under fire. The structural behaviour of a steel structure under fire is rather complicated not only because of the strength degradation of steel at elevated temperatures, but also because of the change in geometry due to thermal expansion. If free expansion is prevented, thermal stress will also be developed. Eurocode 3 Part 1-2 [1] provides reduction factors of yield strength and modulus of elasticity for the stress-strain relationship for steel at elevated temperatures. To determine the strength of steel columns at a specific temperature, the same formulas for calculating the buckling strength at ambient temperature [2] can be adopted. In this paper, a two-dimensional steel frame is made up to demonstrate the effect of a localized fire with different temperatures at a column to the global frame using second-order analysis in which the P- $\Delta$ and the $\mathrm{P}-\delta$ effects are taken into account. Although research on finite element modelling of steel columns and framed structures at elevated temperatures has been carried out extensively over the past three decades, this paper aims to develop a simplified fire engineering approach based on the design values of the material properties given in Eurocode 3 Part 1-2 [1]. 


\section{LITERATURE REVIEW}

Extensive research on large-scaled laboratory tests on unprotected or protected steel structures under fire has been carried out over the past few decades. In general, there are two types of tests. In the first type, the test is carried out in a transient state in which a constant load is applied to the column while the temperature is increased; while in the second type, the test is carried out in a steady state that the temperature is held constant at a pre-determined level and the load is applied incrementally until the column fails. The majority of the fire tests focus on structural behaviour of individual steel members under fire conditions. For example, Franssen et al. [3], Yang et al. [4] and Yang and Hsu [5], etc, carried out laboratory tests on isolated steel columns under fire condition. While most of the design codes [1,6,7] provide design recommendations for fire condition, they are developed mainly based on experimental observations. However, since these tests are carried out on isolated members mainly with concentric loads and simple end conditions, the true interaction between the column and its adjacent members cannot be reflected. Janss [8] conducted research on estimating the effective lengths of steel columns from the experimental data from Janss and Minne [9]. Statistical analysis was carried out to estimate the effective length factors which were found to be in good accordance with the values given in Eurocode 3 Part 1-2 [1] which are 0.5 for continuous columns and 0.7 for columns in the top storey. Ali and O'Connor [10] carried out parametric experimental investigation on rotationally and axially restrained steel columns in fire which were connected to steel plates. With the rotational and axial restraints, additional force is generated during the fire condition. Based on the results, values of effective length factors were proposed for steel columns with different degrees of restraints. Wang and Davies [11] conducted fire tests on column assemblies in which two restraining beams are connected to the web of the column so that rotational restraint about principal major axis is provided. It was concluded that the estimated effective lengths of the steel columns were shorter than that assuming pinned at both ends. Tan et al. [12] also carried out similar research on the structural responses of restrained steel columns over a range of slenderness ratio at elevated temperatures. In their study, the initial crookedness and load eccentricity were carefully examined. Their results pointed out that the presence of these initial imperfections posed an important factor to the failure temperatures of the steel columns. Wald et al. [13] carried out experimental research on full-scale fire tests, known as the Cardington fire tests, which involved an eight-storey steel framed building. Through the laboratory test, the structural behaviours of the beams, columns, connections and composite slabs of the steel-framed structure as a typical office building under fire conditions were carefully studied.

Since full-scale fire tests on structures are expensive and time consuming, numerical methods are more preferable. Wang [14] carried out numerical analysis of the global structural behaviour using the finite element computer program FIREFRAME researched by Wang and Moore [15] and compared the experimental results from the Cardington fire tests. Although numerical results suggested that the slab tensile membrane action enhanced the fire resistance of the steel columns which agreed with the experimental results, structural behaviour of columns could not be assessed due to the relatively low temperature. Chen and Young [16] studied the structural behaviour of high strength steel columns at elevated temperatures using the finite element program ABAQUS [17] with both pinned-end and fixed-end conditions considered. In the analysis, the initial imperfections were taken into account and model for stress-strain relationship of high-strength steel was proposed. The results of the finite element modelling were verified against experimental data of columns at ambient and elevated temperatures available in the literature. It was shown that the European and American specifications [1,7] conservatively predicted the column strengths of high strength steel at elevated temperatures. 


\section{MECHANICAL PROPERTIES OF STEEL AT ELEVATED TEMPERATURES}

This paper adopts the idealized stress-strain relationship of steel at elevated temperatures given in Eurocode 3 Part 1-2 [1]. As shown in Figure 1, at the beginning a linear elastic range is observed with the slope $E_{a, \theta}$ before the proportional limit $f_{p, \theta}$ is reached. After that proportional limit the slope starts to be gentler and finally flatten out at effective yield strength $f_{y, \theta}$ where the strain reaches yield strain. The stress $\sigma$ and the tangent modulus $E_{t, \theta}$ at the nonlinear range are given by the following equations.

$$
\begin{aligned}
& \sigma=f_{p, \theta}-c+\frac{b}{a} \sqrt{a^{2}-\left(\varepsilon_{y, \theta}-\varepsilon\right)^{2}} \\
& E_{t, \theta}=\frac{b}{a} \frac{\varepsilon_{y, \theta}-\varepsilon}{\sqrt{a^{2}-\left(\varepsilon_{y, \theta}-\varepsilon\right)^{2}}}
\end{aligned}
$$

where $\quad \varepsilon_{y, \theta}=0.02$

$$
\begin{aligned}
& a^{2}=\left(\varepsilon_{y, \theta}-\varepsilon_{p, \theta}\right)\left(\varepsilon_{y, \theta}-\varepsilon_{p, \theta}+\frac{c}{E_{a, \theta}}\right) \\
& b^{2}=c\left(\varepsilon_{y, \theta}-\varepsilon_{p, \theta}\right) E_{a_{, \theta}}+c^{2} \\
& c=\frac{\left(f_{y, \theta}-f_{p, \theta}\right)^{2}}{\left(\varepsilon_{y, \theta}-\varepsilon_{p, \theta}\right) E_{a, \theta}-2\left(f_{y, \theta}-f_{p, \theta}\right)}
\end{aligned}
$$

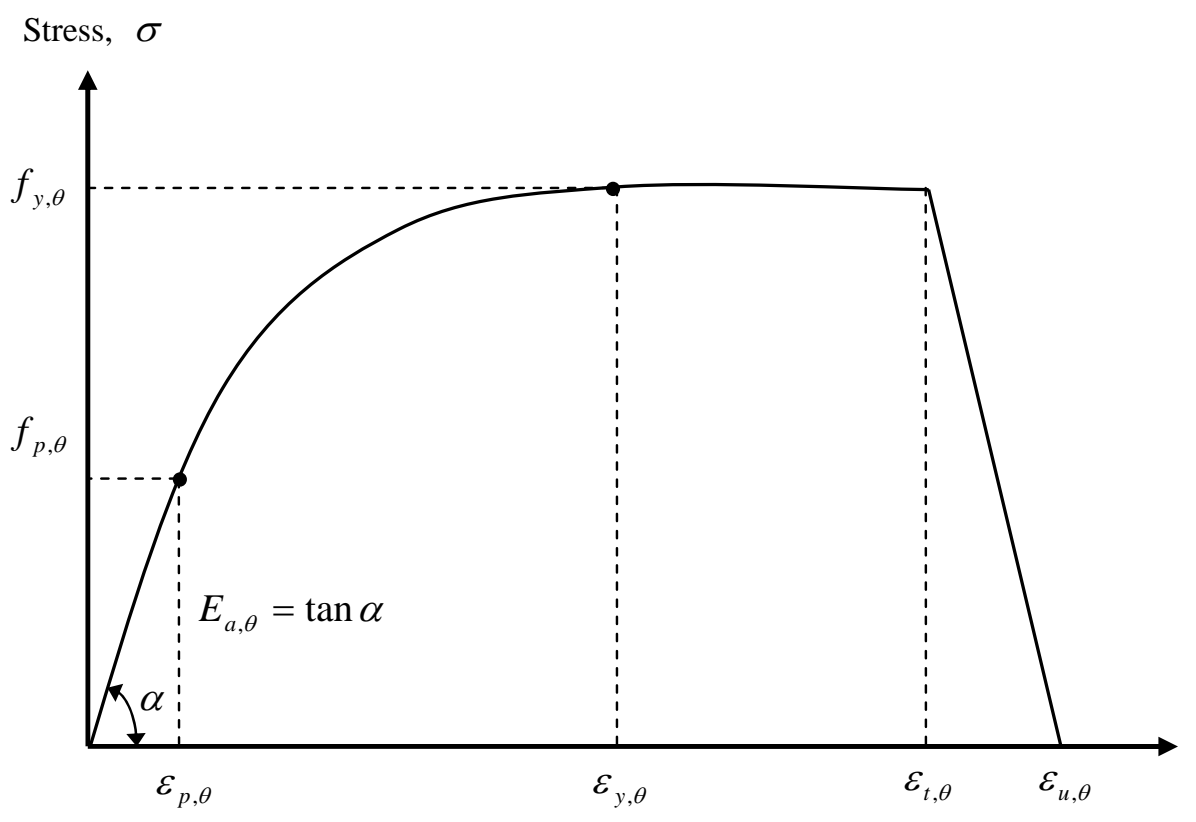

Strain, $\varepsilon$

Figure 1. Stress-strain Relationship for Carbon Steel at Elevated Temperatures 
Notations: $\quad f_{p, \theta}: \quad$ proportional limit

$f_{y, \theta}: \quad$ effective yield strength

$E_{a, \theta}: \quad$ slope of the linear elastic range

$\varepsilon_{p, \theta}: \quad$ strain at proportional limit

$\varepsilon_{y, \theta}: \quad$ yield strain

$\varepsilon_{t, \theta}: \quad$ limiting strain for yield strength

$\varepsilon_{u, \theta}: \quad$ ultimate strain

The mechanical properties of carbon steel at $20^{\circ} \mathrm{C}, 200^{\circ} \mathrm{C}, 400^{\circ} \mathrm{C}, 600^{\circ} \mathrm{C}, 800^{\circ} \mathrm{C}, 1000^{\circ} \mathrm{C}$ and $1200^{\circ} \mathrm{C}$ given in Eurocode 3 Part 1-2 [1] are summarized in Table 1. For temperatures below $400^{\circ} \mathrm{C}$, an alternative stress-strain relationship for carbon steel allowing for strain hardening is provided. However, for simplicity as allowed in the design code [1], strain-hardening of steel is not considered in the investigation. With these properties, the exact stress-strain relationship at the nonlinear range where $\varepsilon_{p, \theta}<\varepsilon<\varepsilon_{y, \theta}$ at different heat levels can be calculated by the above formulas. It should be noted that the nonlinear stress-strain relationship applies to both tension and compression. For thermal properties, in Eurocode 3 Part 1-2 [1], the relative thermal elongation is given by Eqs. 3a-3c. However, in this paper, a coefficient of linear thermal expansion of $1.4 \times 10^{5}$ is adopted for simplicity.

For $20^{\circ} \mathrm{C} \leq \theta_{a} \leq 750^{\circ} \mathrm{C}$,

$$
\Delta l / l=1.2 \times 10^{-5} \theta_{a}+0.4 \times 10^{-8} \theta_{a}^{2}-2.416 \times 10^{-4}
$$

For $750^{\circ} \mathrm{C} \leq \theta_{a} \leq 860^{\circ} \mathrm{C}$,

$\Delta l / l=1.1 \times 10^{-2}$

For $860^{\circ} \mathrm{C} \leq \theta_{a} \leq 1200^{\circ} \mathrm{C}$,

$$
\Delta l / l=2 \times 10^{-5} \theta_{a}-6.2 \times 10^{-3}
$$

where $\quad l$ is the length at ambient temperature

$\Delta l$ is the temperature induced elongation

$\theta_{a}$ is the steel temperature $\left({ }^{\circ} \mathrm{C}\right.$ )

Table 1. Mechanical Properties of Steel at Elevated Temperatures

\begin{tabular}{|c|c|c|c|}
\hline $\begin{array}{c}\text { Steel } \\
\text { Temperature } \\
\theta\left({ }^{\circ} \mathrm{C}\right)\end{array}$ & $\begin{array}{c}\text { Effective Yield Strength } \\
f_{y, \theta} / f_{y}\end{array}$ & $\begin{array}{c}\text { Proportional } \\
\text { Limit } \\
f_{p, \theta} / f_{y}\end{array}$ & $\begin{array}{c}\text { Slope of the Linear } \\
\text { Elastic Range } \\
E_{a, \theta} / E_{a}\end{array}$ \\
\hline 20 & 1.000 & 1.000 & 1.000 \\
\hline 200 & 1.000 & 0.807 & 0.900 \\
\hline 400 & 1.000 & 0.420 & 0.700 \\
\hline 600 & 0.470 & 0.180 & 0.310 \\
\hline 800 & 0.110 & 0.050 & 0.090 \\
\hline 1000 & 0.020 & 0.025 & 0.045 \\
\hline 1200 & 0.000 & 0.000 & 0.000 \\
\hline
\end{tabular}




\section{THE SECOND-ORDER ANALYSIS BY NIDA}

NIDA [18] is a commercial nonlinear analysis and design software developed by the Hong Kong Polytechnic University which can achieve performance-based design. By considering the second-order P- $\Delta$ and $\mathrm{P}-\delta$ effects with allowance for the initial member imperfections during analysis, the failure load of the structure can be accurately determined without considering the effective length for individual column members. In the current study, the analysis adopts a similar approach carried out by Burgess et al. [19] where a secant stiffness matrix, instead of a tangent stiffness matrix, is used to trace the equilibrium path of the structure under fire with the following modifications in NIDA [18]:

\subsection{The Modified Modulus of Elasticity}

In each load cycle during the analysis, the secant stiffness is updated using the modified modulus of elasticity $\bar{E}$ to account for the material strength degradation. Considering a column is stocky enough that the deformation is insensitive to the initial imperfection, at any load level, the applied stress $\sigma$ can be calculated as

$\sigma=\frac{F_{c}}{A}$

When the applied stress $\sigma$ is greater than the proportional limit $f_{p, \theta}$ but smaller than the effective yield strength $f_{y, \theta}$, the stress-strain relationship is no longer linear and the equivalent strain can be calculated by rearranging terms from Eq. 1 as

$$
\varepsilon=\varepsilon_{y, \theta}-\sqrt{a^{2}-\frac{a^{2}}{b^{2}}\left(\sigma+c-f_{p, \theta}\right)^{2}}
$$

At the nonlinear range, the tangent modulus can thus be calculated by substituting $\varepsilon$ into Eq. 2 while the modified modulus of elasticity $\bar{E}$ for a member under pure compression can be calculated by dividing $\sigma$ in Eq. 4 by $\varepsilon$ in Eq. 5 as

$\bar{E}=\frac{\sigma}{\varepsilon}$

Next, considering a beam subject to uniform bending moment, the strains are zero at the neutral axis and vary linearly with distance from the neutral axis. At elevated temperatures when the beam is stressed beyond the proportional limit, the moment $M_{\theta}$ at a given curvature is calculated from the integration of the exact stress calculated from Eq. 1 times the distance from the neutral axis as in Eq. 7 and the moment capacity $M_{c, \theta}$ is taken as the moment where the extreme fiber reaches the effective yield strength.

$M_{\theta}=\int_{A} \sigma y d A$

Alternatively, since the stress distribution is symmetric about the neutral axis for doubly symmetric sections, the moment in Eq. 7 can be rewritten in terms of strain $\varepsilon$ as follows. 
$M_{\theta}=2\left(\frac{D / 2}{\varepsilon_{\max }}\right)^{2}\left[\int_{0}^{\varepsilon_{p, \theta}} t(\varepsilon) \varepsilon^{2} \cdot E_{a, \theta} d \varepsilon+\int_{\varepsilon_{p, \theta}}^{\varepsilon_{\max }} t(\varepsilon) \cdot \sigma \cdot \varepsilon d \varepsilon\right]$

where $D$ is the depth of the section

$t(\varepsilon)$ is the thickness of the web or width of the flange

$\varepsilon_{\max }$ is the maximum strain at the outermost fibre of the section

Therefore, the modified modulus of elasticity $\bar{E}$ will be given by

$\bar{E}=\frac{M_{\theta}}{\rho \cdot I}$

where $\rho$ is the curvature of the beam.

With a similar approach, the modified modulus of elasticity for element under both axial force and moment can be calculated using Eqs. 7 and 9. However, special attention has to be made to the unsymmetrical stress distribution across the section due to the presence of the axial force. The modified modulus of elasticity $\bar{E}$ is incorporated into NIDA [18] to achieve the fire design.

\subsection{The PEP Element}

When performing second-order analysis using NIDA [18], the PEP (Pointwise Equilibrating Polynomial) element which was well researched by Chan and Zhou [20,21] is used. As shown in Figure 2, the shape function of the lateral displacement $v$ along one principal plane of the element is assumed to be a fifth-order polynomial as follows.

$v=a_{0}+a_{1} x+a_{2} x^{2}+a_{3} x^{3}+a_{4} x^{4}+a_{5} x^{5}$

The initial imperfection along the member is also included in the PEP element as follows.

$v_{0}=\delta_{0}\left(1-\frac{4 x^{2}}{L^{2}}\right)$

where $\quad-\frac{L}{2} \leq x \leq \frac{L}{2}$

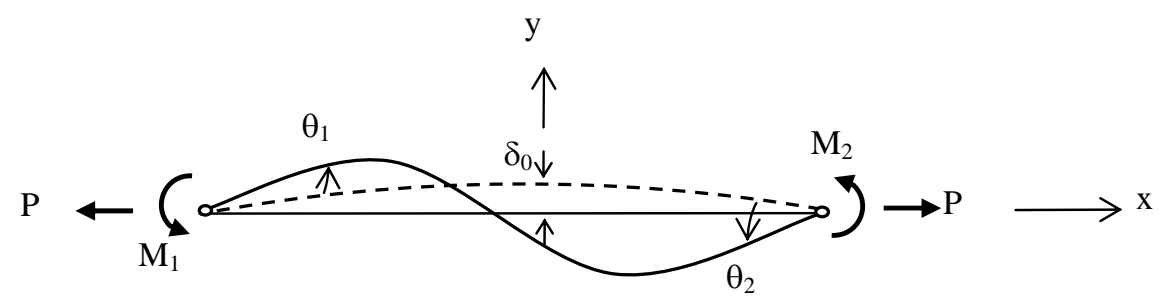

Figure 2. The PEP Element Model 
The detailed mathematical derivation of the tangent stiffness matrix and the secant stiffness matrix from the total potential energy function are well documented in references [20] and [21]. In some design codes [2,22], when performing second-order analysis, the inclusion of initial curvature is mandatory. Originally, this PEP element fulfils the requirement because the initial curvature is already included in the shape function. However, it should be noted that for members under fire condition subject to a non-uniform moment distribution, since stress levels along the member are different, the modified modulii of elasticity along the member are therefore different, they should be split into a number of elements small enough that uniform bending moment can be assumed for each element and the initial curvature should be considered carefully by adjusting the coordinates of each node along the member.

\subsection{Analysis Procedure}

In a conventional second-order elastic analysis under normal condition, since the material is assumed to be perfectly elastic throughout the analysis, only the geometry change is considered. Since the final geometry is unknown during the initial formulations, numerical solution technique must be adopted in which the analysis is carried out in an incremental-iterative manner. In short, the load is applied incrementally and in each load increment, iteration is repeatedly carried out until an equilibrium point is reached. In the next load cycle, the stiffness is calculated based on the updated geometry from the preceding cycle. In the present study, since the nonlinearity of the material under fire is considered, when the stress is beyond the proportional limit, the material properties are to be updated in each load cycle. Among various numerical schemes available in NIDA [18] for carrying out a second-order analysis, the load-control Newton-Raphson method is widely used today for both design and research purposes because of its simplicity. The main feature of this method is the numerical procedure iterates at a constant load level in each cycle; therefore it may result in divergence when the applied load is reaching the limit point. However, in the present study, the Newton-Raphson method is adequate since the failure load occurs before the limit point is reached. Figure 3 schematically shows the incremental-iterative scheme of the conventional Newton-Raphson method. A simple flowchart in Figure 4(a) highlights the key steps of the iteration process. For a conventional second-order elastic analysis under ambient temperature condition where only one plastic hinge is allowed to form, the section capacity check in Eq. 12 is always required to indicate when a member fails. When $\varphi$ is equal to unity, the applied load is considered as the failure load of the structure and the structural behaviour after the failure load is considered meaningless. Although member by member section capacity check is still required, the member resistance check involving manual calculation of effective length is no longer needed since the second-order moments can be accurately calculated at the instant the analysis is performed.

$$
\frac{F_{c}}{A \cdot p_{y}}+\frac{\bar{M}_{x}+F_{c}\left(\delta_{x}+\Delta_{x}\right)}{M_{c x}}+\frac{\bar{M}_{y}+F_{c}\left(\delta_{y}+\Delta_{y}\right)}{M_{c y}}=\varphi
$$

where $F_{c}$ is the axial compression force

$A$ is the gross section area

$p_{y}$ is the design strength

$M_{c i}$ is the moment capacity about $i$-axis

$\bar{M}_{i}$ is the first-order moment about $i$-axis

$\delta_{i}$ and $\Delta_{i}$ are the relative and the global displacements about the major axis contributing to the second-order moments

$\varphi$ is the section capacity factor 
Applied Load, $[F]$

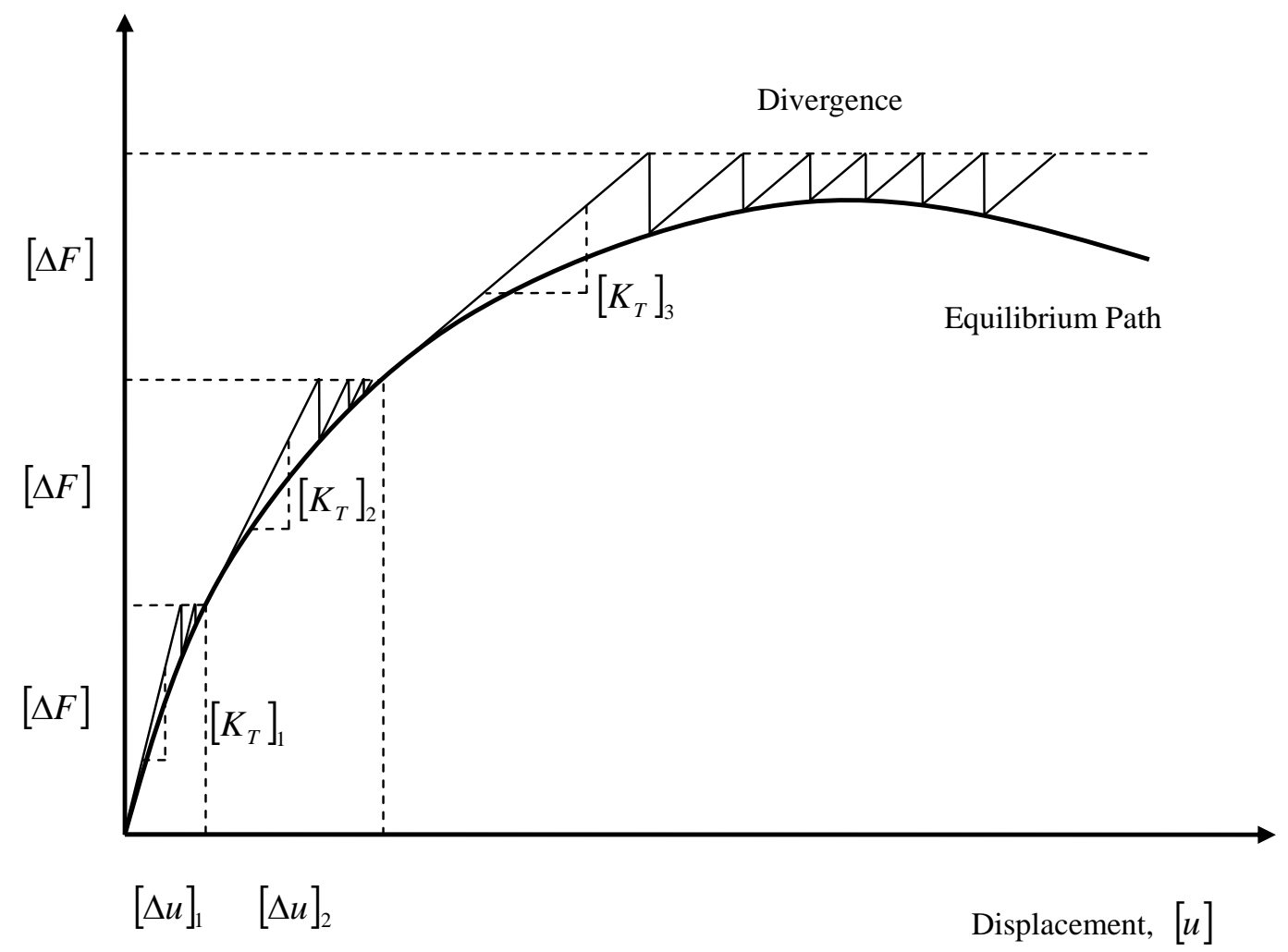

Figure 3. The Newton-Raphson Numerical Procedure

For second-order elastic analysis under fire condition, considering only one principal plane, Eq. 12 can be modified to Eq. 13 as follows to indicate the material across the section starts to behave nonlinearly at elevated temperatures.

$\frac{F_{c}}{A \cdot f_{p, \theta}}+\frac{\bar{M}_{x}+F_{c}\left(\delta_{x}+\Delta_{x}\right)}{f_{p, \theta} \cdot Z_{x}}=\varphi^{\prime}$

where $Z_{x}$ is the elastic modulus of the section

While $\phi$ in Eq. 12 greater than 1.0 means failure, $\varphi^{\prime}$ in Eq. 13 greater than unity indicates the slope of the stress-strain curve of the material is no longer constant. The modified modulus of elasticity $\bar{E}$ in the secant stiffness has to be updated in each load cycle. To achieve this, firstly, a curvature $\rho$ is assumed by dividing the moment at that load cycle by the flexural rigidity EI from the previous load cycle. Secondly, the strain across the section can be calculated by multiplying the curvature times the distance $y$ from the neutral axis. Thirdly, the stress at distance $y$ can be calculated from Eq. 1 and thus the moment can be found by Eq. 7. At this point, the moment is unbalanced. Therefore, iterations are performed to obtain the value of the modified modulus of elasticity $\bar{E}$ so that the moment calculated from Eq. 7 is equal to the applied moment. Similar to the conventional second-order analysis, failure occurs when the maximum stress reaches the effective yield strength. The flowchart in Figure 4(a) is modified to Figure 4(b) to demonstrate the key steps of the second-order analysis dealing with elevated temperatures. 


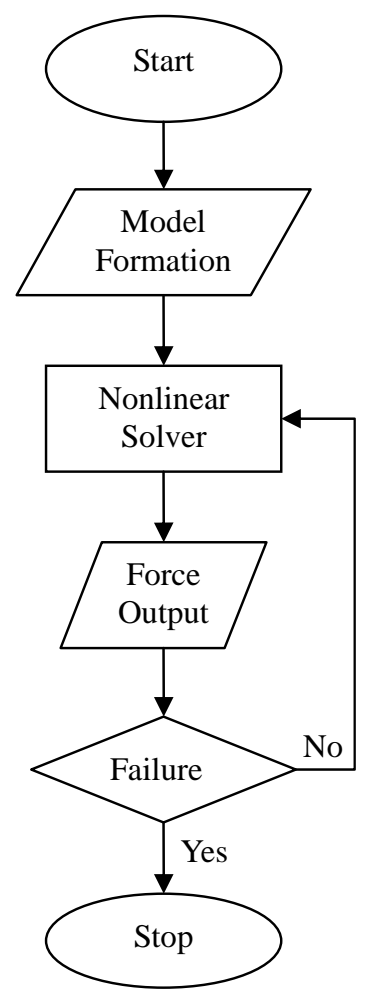

Figure 4(a). Flowchart of Second-order Elastic Analysis at Room Temperature

\subsection{Illustrative Examples}

The following examples demonstrate the structural performances of members or frames incorporating material nonlinearity at elevated temperatures ranging from $20^{\circ} \mathrm{C}$ to $600^{\circ} \mathrm{C}$. Temperatures above $600^{\circ} \mathrm{C}$ are not considered since the effective yield strength is already reduced dramatically. The following assumptions are made.

1. Sections are doubly-symmetric.

2. Uniform heat distribution along the member is assumed so no temperature zone is divided along the member.

3. Residual stress is not considered.

4. The self-weight of the material is ignored.

5. The connections are fully protected against fire so that they are unaffected by elevated temperatures.

6. The frames are two-dimensional so out-of-plane buckling is not considered.

7. Planes of cross-section remain plane after deformation.

8. Local buckling failure mode is not considered. 


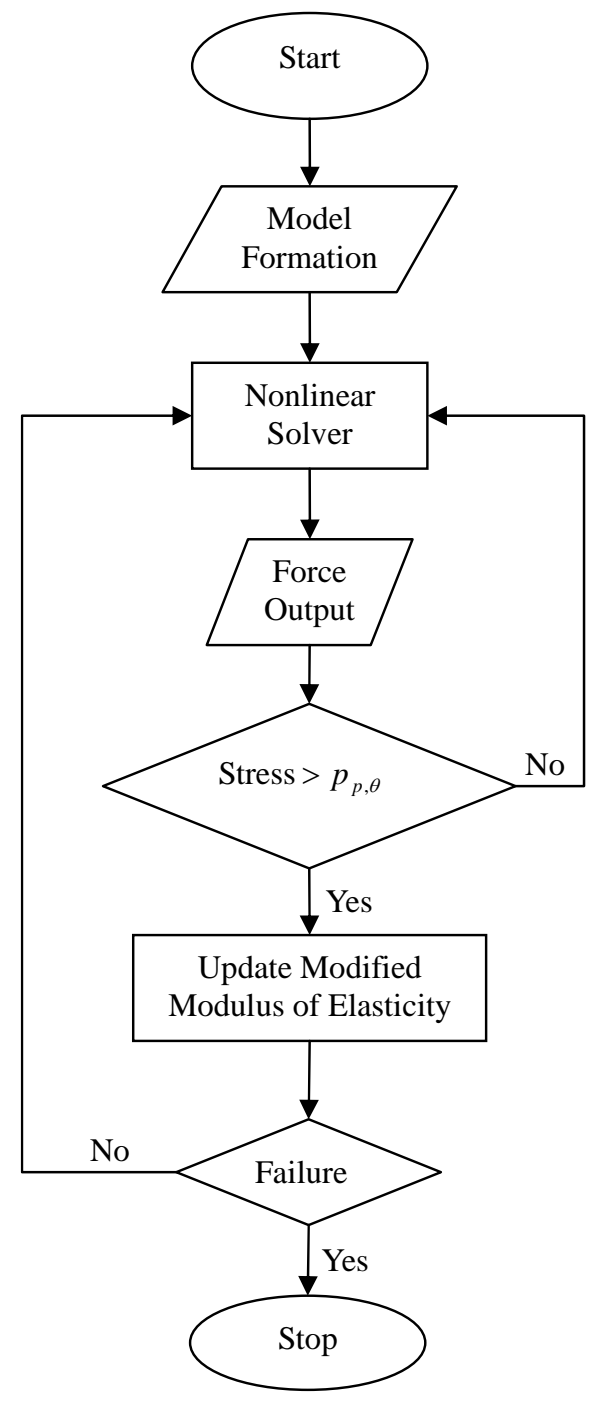

Figure 4(b). Flowchart of Second-order Analysis at Elevated Temperature

\subsubsection{Example 1 - A very stocky column}

A 1m-long pin-ended column of section $203 \times 203 \times 46$ UC $\left(I_{x}=4570 \mathrm{~cm}^{4}, Z_{x}=450 \mathrm{~cm}^{3}\right.$, $A=58.7 \mathrm{~cm}^{2}$ ) in S275 is used as a benchmark example to verify the structural analysis under the effect of elevated temperatures. In this case, since the column is free to expand, thermal stress will not be developed. The column is stocky enough so that it is insensitive to the initial imperfection and the deformation is mainly due to axial shortening. Since the stress along the member is uniform so one PEP element per member is enough to capture the structural behaviour of a stocky column under uniform elevated temperature. The column is compressed at a constant temperature at $20^{\circ} \mathrm{C}$, $200^{\circ} \mathrm{C}, 400^{\circ} \mathrm{C}$ and $600^{\circ} \mathrm{C}$ respectively. The failure load can be simply taken as the squash load as

$$
P_{y, \theta}=A \cdot p_{y, \theta}
$$

Before the proportional limit is reached, the equilibrium path can be traced using the conventional numerical approach with the Young's modulus replaced by the slope of linear elastic range $E_{a_{\theta}}$ given in Table 1. Once the proportional limit is reached, with the modified modulus of elasticity $\bar{E}$ 
calculated from Eq. 6 updated in the secant stiffness in the load cycle, the load-deflection relationship after the proportional limit can be traced using the modified numerical procedure. Figure 5 presents the load-deflection curves at different temperatures from the results calculated numerically by the modified second-order analysis and theoretically from Eq. 1. The numerical solutions are in line with the theoretical results showing that the modified second-order analysis is able to capture the nonlinear behaviour when the column is under axial force with negligible second-order moment.

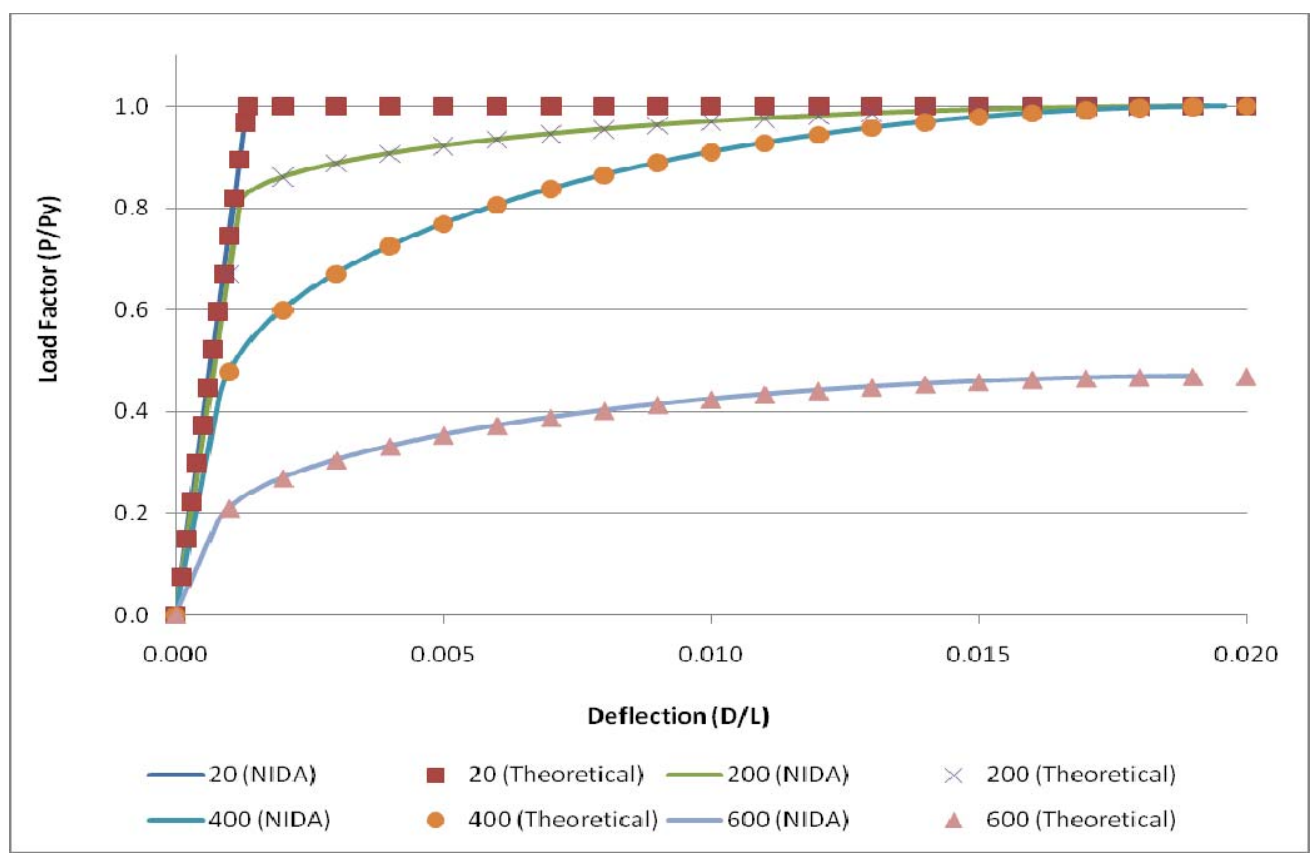

Figure 5. Load-deflection Curve of $203 \times 203 \times 46 U C$ at Elevated Temperatures

\subsubsection{Example 2 - A simply supported beam subject uniform moment}

A 3m-long simply supported beam of section $203 \times 133 \times 30 \mathrm{UB}\left(I_{x}=2900 \mathrm{~cm}^{4}, Z_{x}=280 \mathrm{~cm}^{3}\right.$, $S_{x}=314 \mathrm{~cm}^{3}, A=38.2 \mathrm{~cm}^{2}$ ) in $\mathrm{S} 275$ subject to uniform bending moment is used in this example. The beam is assumed to be laterally fully restrained so that the failure mode of lateral-torsional buckling can be ignored. Similar to Example 1, since the bending stress along the member is uniform, one PEP element per member is adequate to capture the structural behaviour of the beam under elevated temperatures. When the bending stress of the outermost fibre reaches proportional limit given in Table 1, the modified modulus of elasticity $\bar{E}$ calculated from Eq. 9 is adopted across the whole section in each load cycle. The moment-curvature relationships at $20^{\circ} \mathrm{C}, 200^{\circ} \mathrm{C}$, $400^{\circ} \mathrm{C}$ and $600^{\circ} \mathrm{C}$ are plotted in Figure 6. Results suggest that the replacement of the slope of the linear elastic range $E_{a, \theta}$ by the modified modulus of elasticity $\bar{E}$ at elevated temperatures provides a reasonable estimate on the moment-curvature relationship. However, for beam subject to non-uniform moment, it is unwise to use one single value of effective young modulus along the whole member because when the axial strain varies along the member the corresponding tangent modulus also varies. Therefore, more elements should be used so that different values of tangent modulii can be observed along the member and thus the result will be more accurate. Burgess et al. [19] suggested that for practical purposes the optimal number of elements to obtain satisfactory accuracy is between 10 and 20 . 


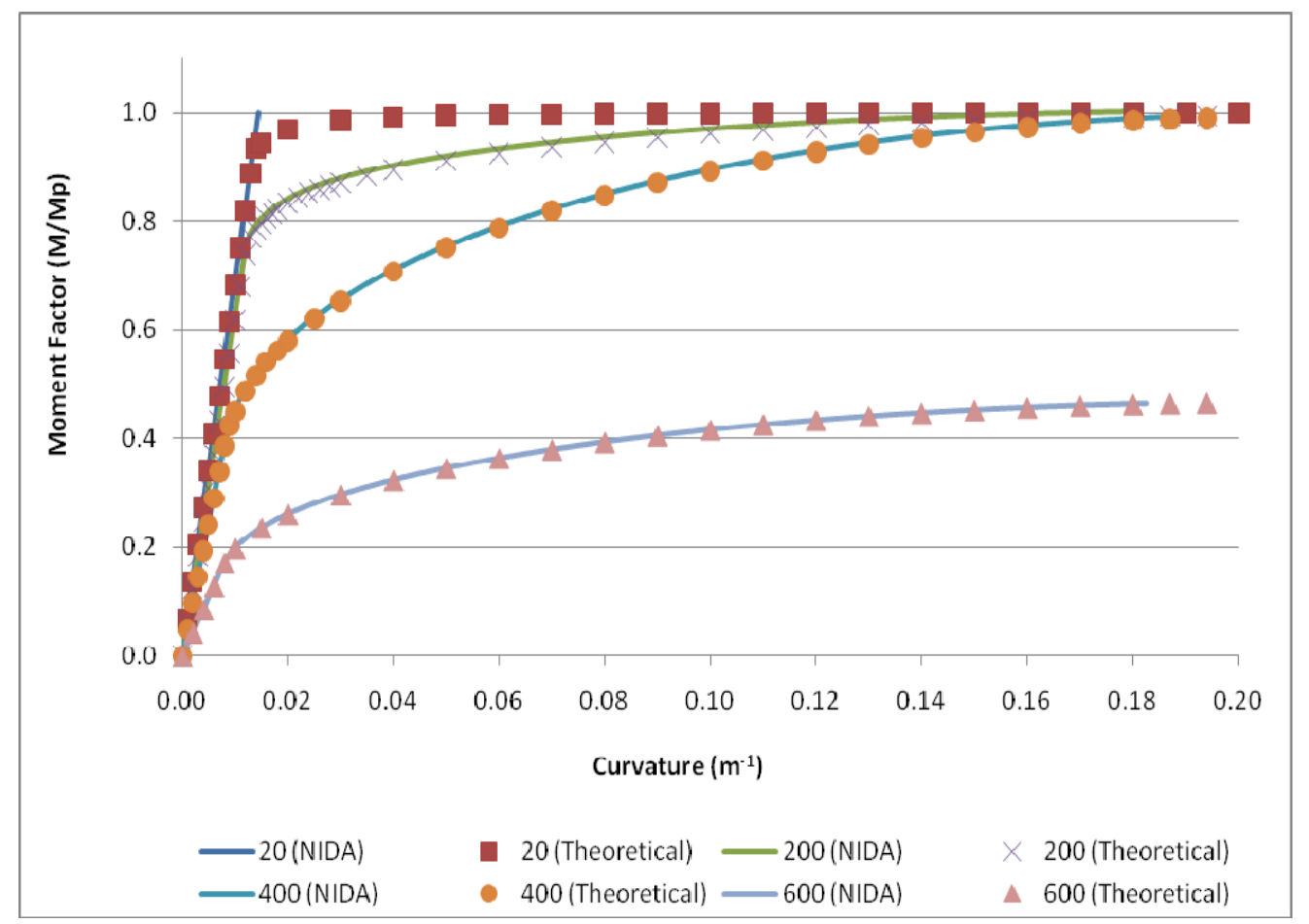

Figure 6. Moment-curvature Relationship of $203 \times 133 \times 30$ UB at Elevated Temperatures

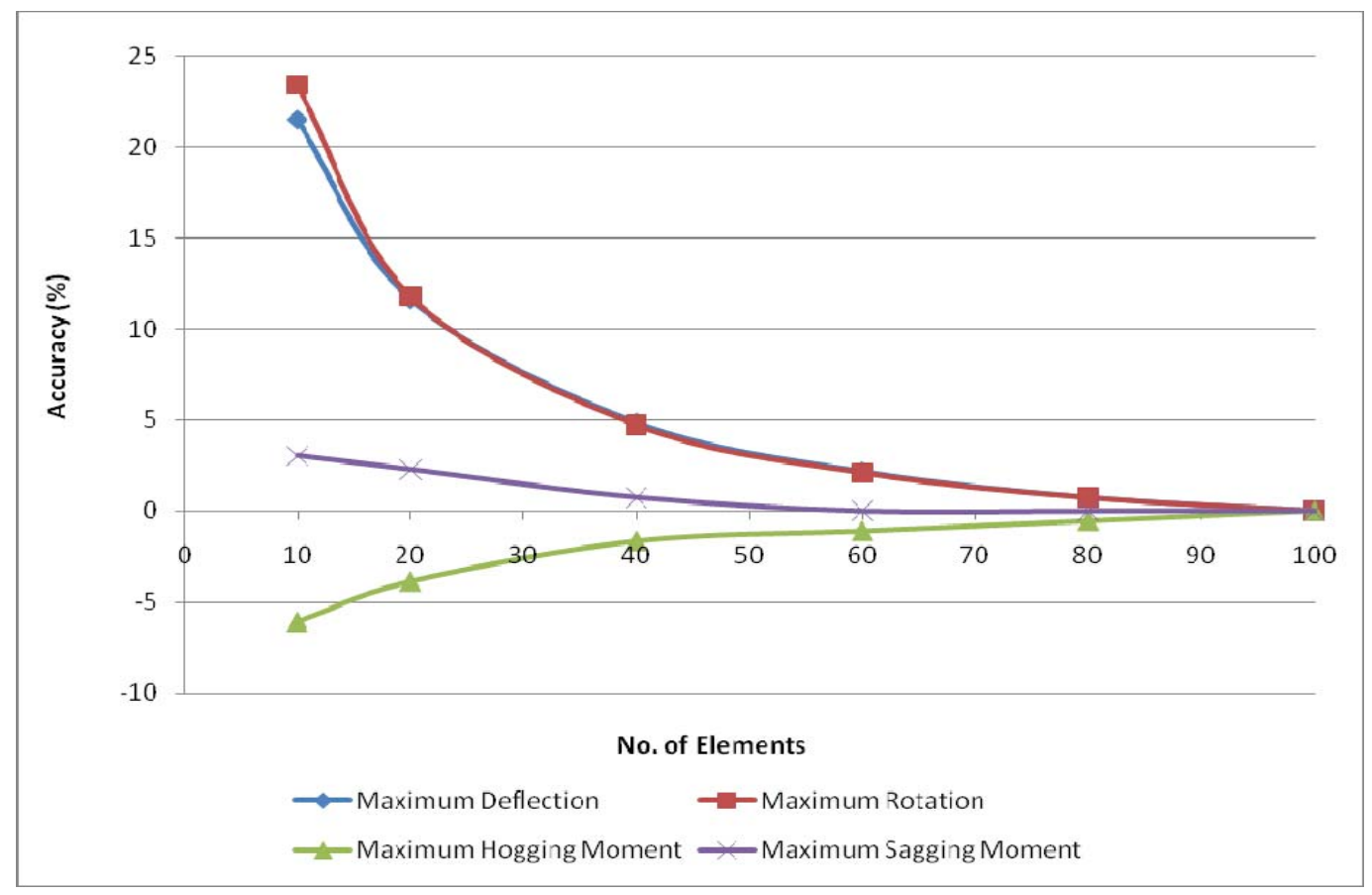

Figure 7. Percentage of Accuracy against No. of Elements of a Propped Cantilever 


\subsubsection{Example 3 - A propped cantilever with uniformly distributed load}

A 5-m propped cantilever under uniformly distributed load of section $457 \times 153 \times 60$ UB is used in this example. Unlike the previous example, this member is statically indeterminate so the bending moment diagram and the material properties mutually affect each other. The bending moment is based on the deformation compatibility of the beam; at the mean time, the deformation depends on the flexural rigidity of the beam. Therefore, the accuracy of the fire analysis will largely depends on the number of elements used per member. Figure 7 shows the accuracy against number of elements of the beam at $600^{\circ} \mathrm{C}$. As can be seen from the results, when the number of elements is 20 , the percentage of accuracy of the maximum hogging and sagging moments fall into a reasonable range of less than $4.0 \%$ which is acceptable for practical design purposes.

\subsubsection{Example 4-A non-slender column with axial load}

A 3-m $203 \times 203 \times 46$ UC column is subject to an axial load. In this case, the failure load is influenced by the magnitude of the initial curvature. The presence of the initial curvature will induce a second-order moment. The slenderness ratio falls into a non-slender range about 34.0 so that the column is subject to predominately axial force. To obtain a satisfactory accuracy, the column is split into 20 elements. It should be noted that under normal circumstances when one element per member is used, the initial curvature is already taken care of by the PEP element. However, since in this example the member is split into a number of elements, the magnitude of the initial curvature given in the CoPHK [21] is considered by adjusting the coordinates of the nodes. It should be also noted that according to BS5950-8:1990 [6], when calculating the structural performance in fire, one should consider the strain limit. Depending on the condition of the member, the strain should be limited to $0.5 \%, 1.5 \%$ or $2.0 \%$. In this case the limiting strain of an unprotected column should be taken as $0.5 \%$. However, for research purposes, strain limit of $2.0 \%$ is used in this example. Figures 8(a) and 8(b) respectively show the load against vertical deflection at the upper column end and the load against horizontal deflection at the mid-length of the column at elevated temperatures. Unlike the stocky column used in Example 1, the initial curvature is important here to trigger the bending once the load is applied; bending stress is developed across the section and the magnitude of the stress varies along the member as the $\mathrm{P}-\delta$ moment is zero at the end supports and maximum at the mid-length. Therefore, more elements per member are used to account for the changing material properties along the member under different stress levels.

\subsubsection{Example 5-A multi-storey frame}

A three-storey four-bay frame consisting of $203 \times 133 \times 30$ UB as beams and $203 \times 203 \times 46$ UC as columns is shown in Figure 9 with the dimensions indicated. Axial forces of $0.5 F$ are applied at nodes (11) and (15) and $F$ at nodes (12), (13) and (14) and no force is applied to the beam members. A localized fire starts at column C8 and it is assumed to be contained in the region. Similar to Example 4, C8 is divided into 20 elements to achieve a satisfactory accuracy of modelling of the material nonlinearity while the rest of the structure remains one element per member. Figures 10(a) and 10(b) respectively show the relationship of the applied load against vertical deflection at the top and horizontal deflection at the mid-length of column $\mathrm{C} 8$ at $20^{\circ} \mathrm{C}$, $200^{\circ} \mathrm{C}, 400^{\circ} \mathrm{C}$ and $600^{\circ} \mathrm{C}$. It is found that the column in Example 5 can sustain a greater applied force than that in Example 4 especially at higher temperatures despite both columns are the same. Figure 11 plots the beam tension over column load at faiure vs temperature. The ratio increases rapidly at higher temperature. It is suggested when the load is applied gradually at elevated temperatures a large displacement occurs which induces tensile membrane action. In other words, the excessive load from the column is redistributed to the members adjoining the column. 


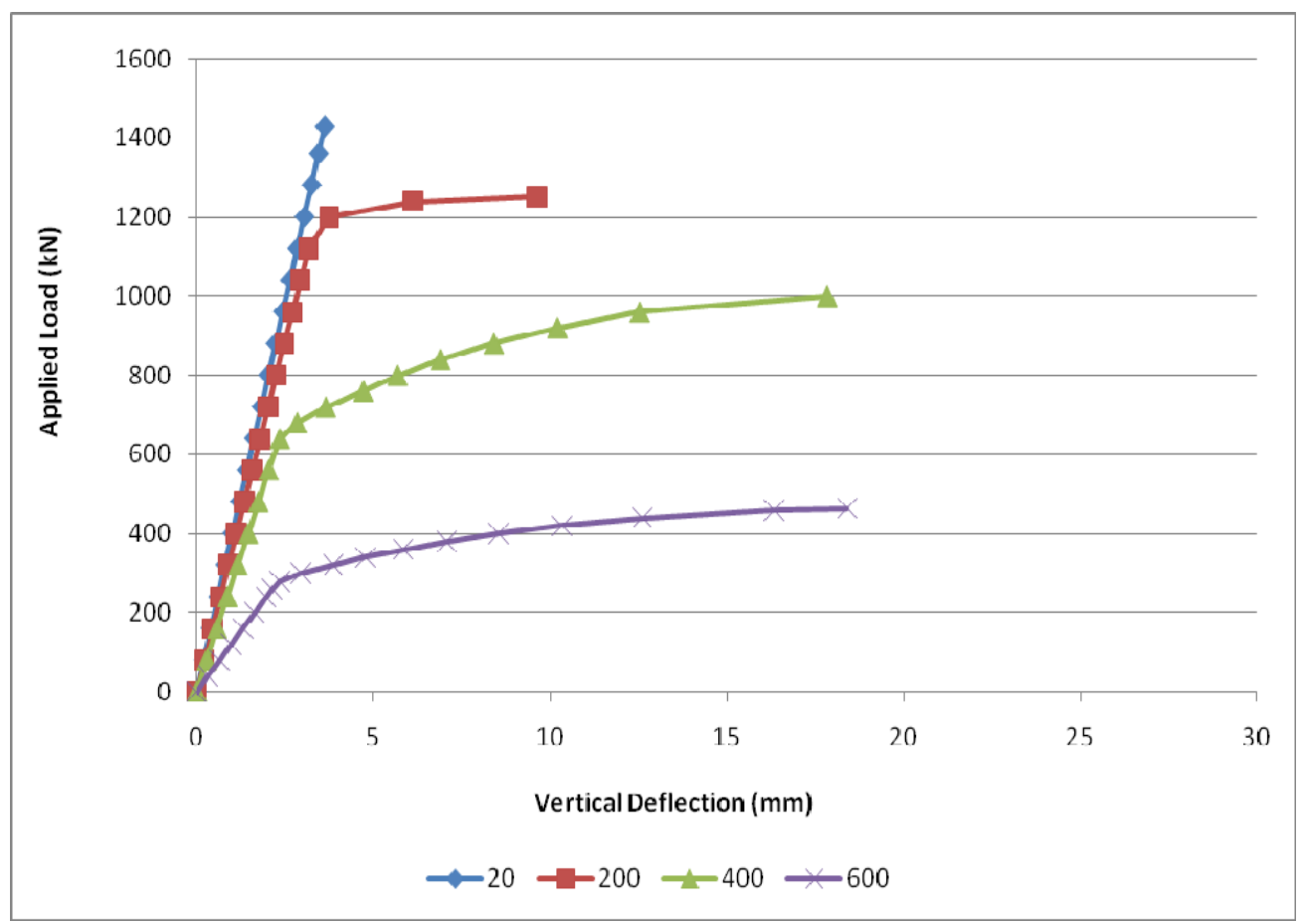

Figure 8(a). Applied Load versus Vertical Deflection of $203 \times 203 \times 46 U C$ at Elevated Temperatures

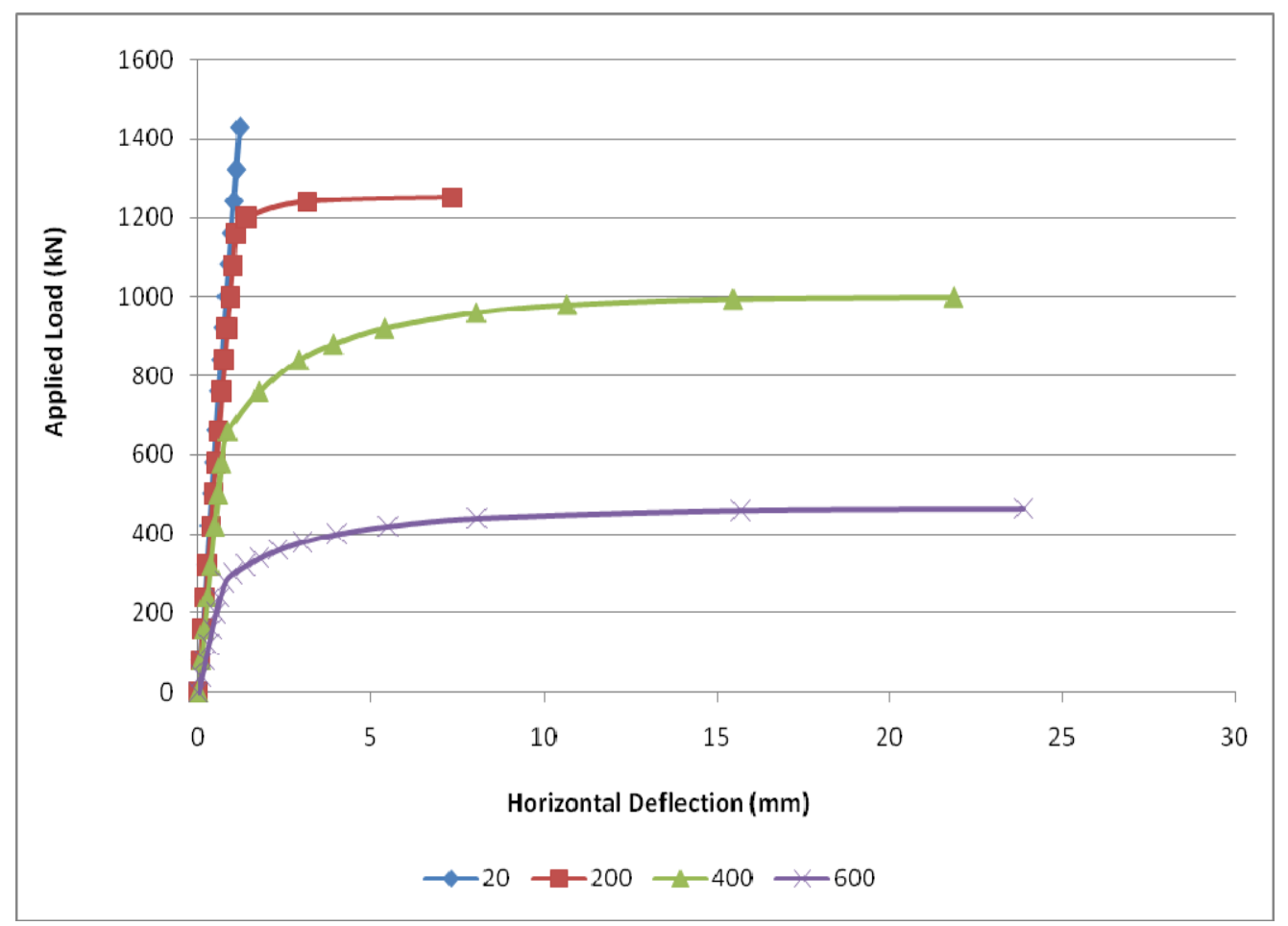

Figure 8(b). Applied Load versus Horizontal Deflection of $203 \times 203 \times 46 U C$ at Elevated Temperatures 


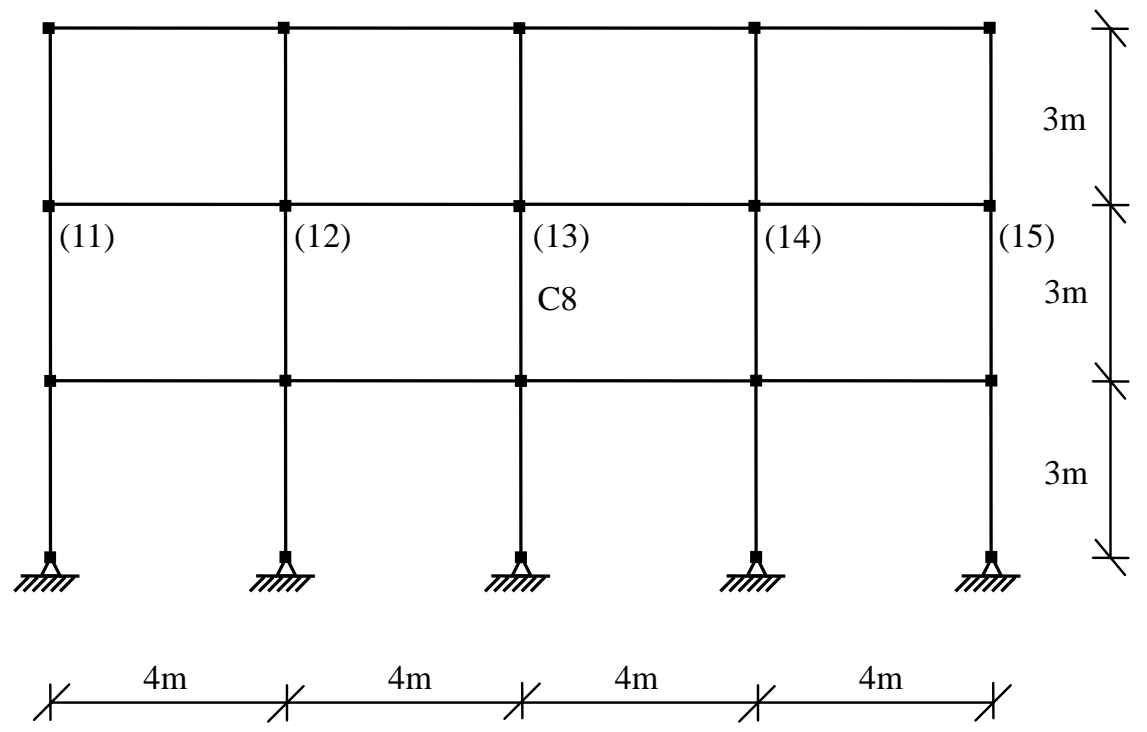

Figure 9. A Three-storey Four-bay Frame

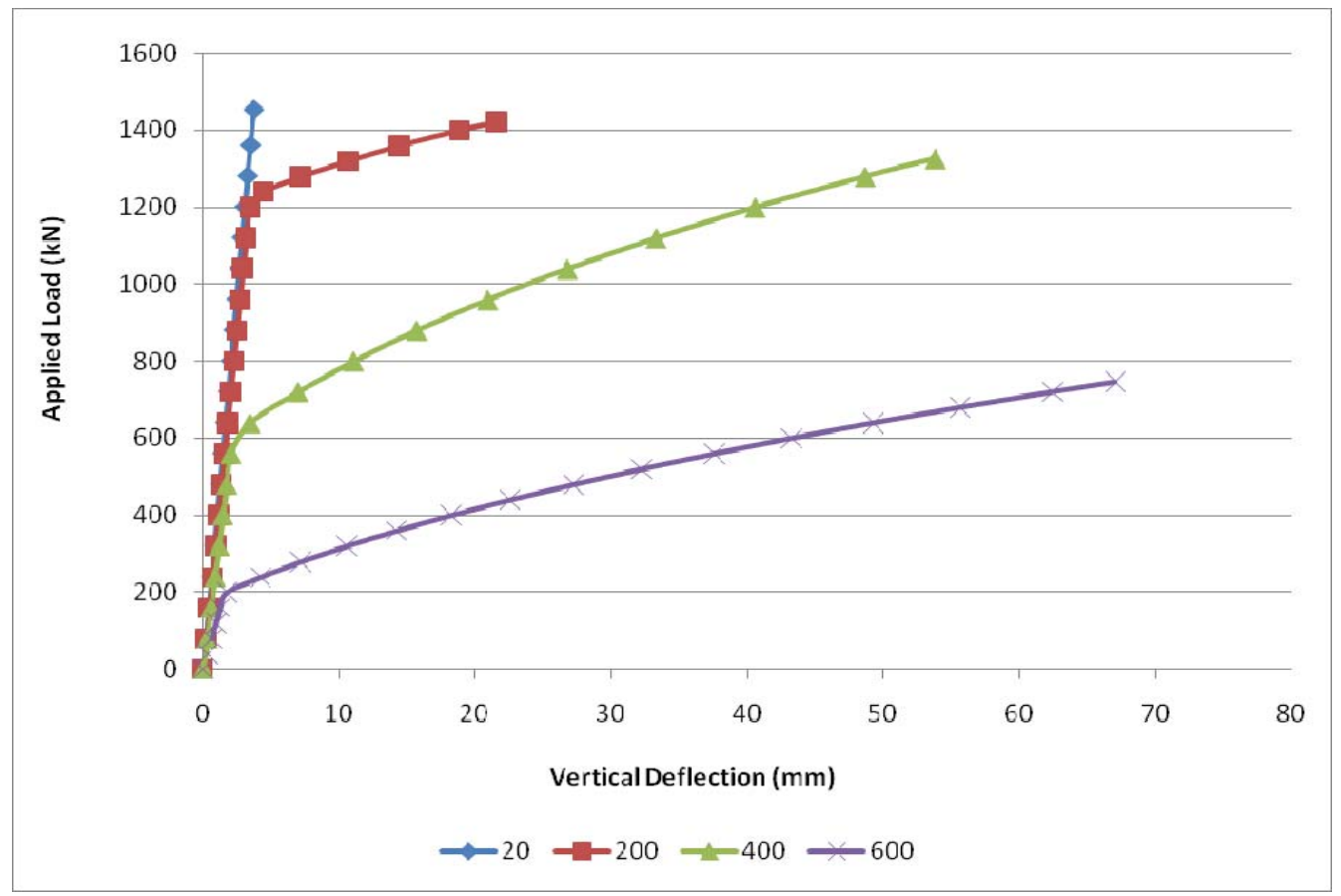

Figure 10(a). Applied Load versus Vertical Deflection of Column “C8” at Elevated Temperatures 


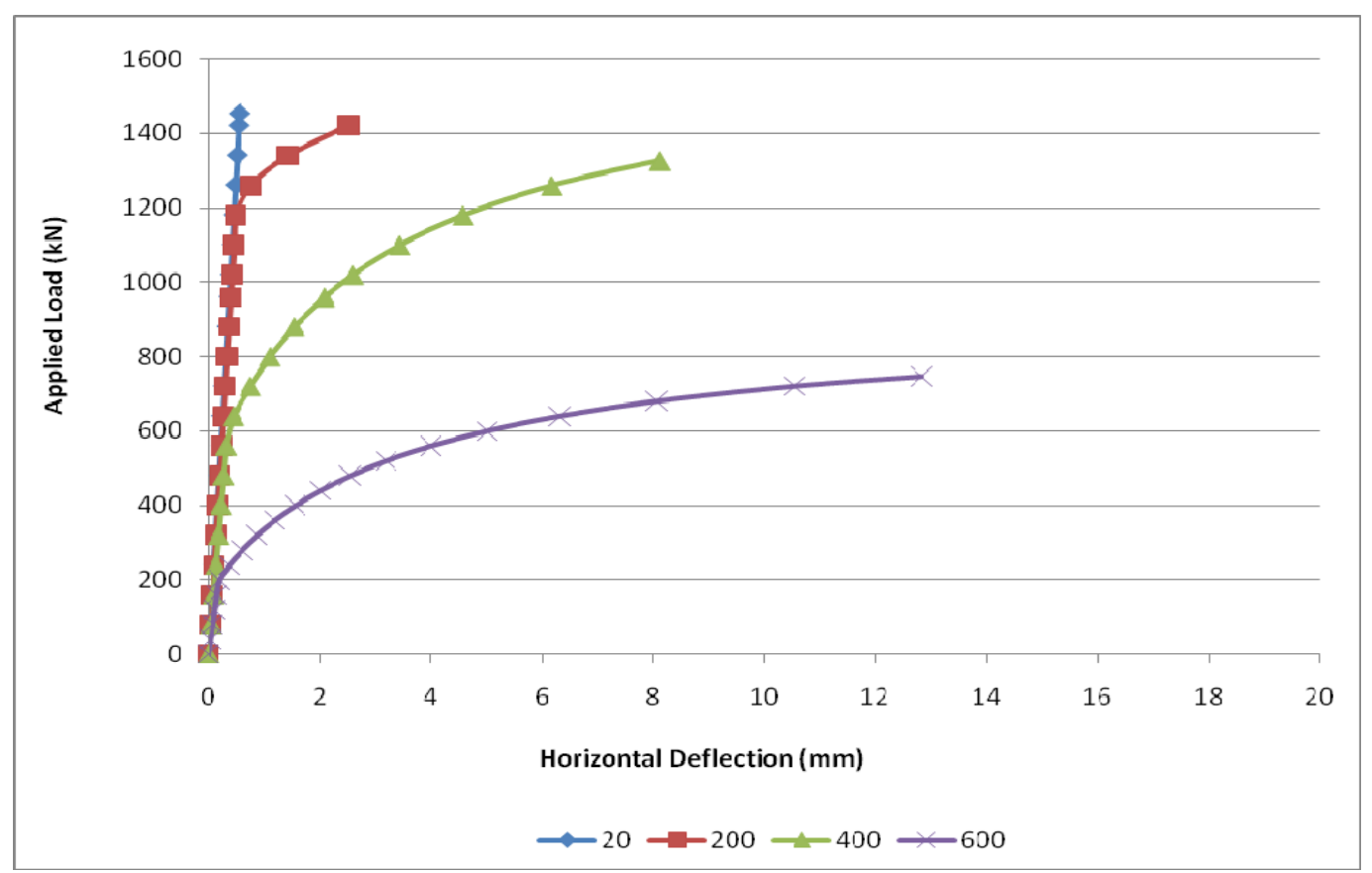

Figure 10(b). Applied Load versus Horizontal Deflection of Column “C8” at Elevated Temperatures

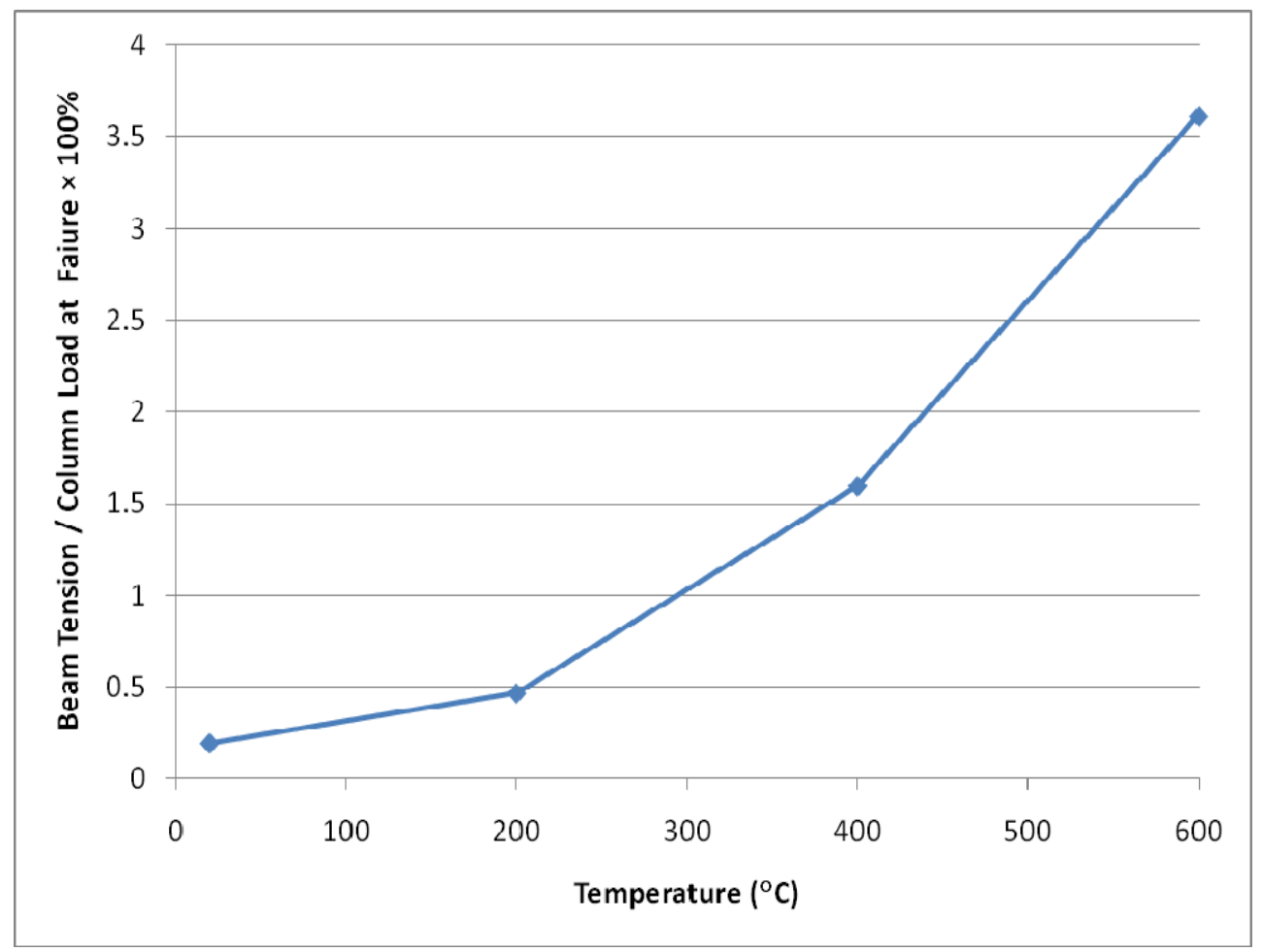

Figure 11. Beam Tension over Column Failure Load vs Temperature 


\section{COMPARISON AND DISCUSSION}

In the study, the analysis is carried out with increasing load under constant temperature. It is found that at higher temperatures a column in a frame is able to take a higher applied force than it is alone because the applied force is actually shared by the connecting members in the form of tensile membrane action. Figure 12 plots the failure load versus temperature of the steel columns in Example 4 and 5. It can be seen that the columns in Example 5 have higher failure loads than those in Example 4 especially at higher temperatures suggesting that the presence of adjoining unheated members greatly increases the failure load of the column. In the mean time, the failure loads are estimated according to Eurocode 3 [1] taking $0.5 \mathrm{~L}$ as the effective length of the steel column are also shown in Figure 12. Comparing the failure loads found by the proposed method using NIDA [18] and Eurocode 3 [1], it can be seen that the proposed method provides a reasonable estimates for column failure loads under fire condition except when the temperature is at $200^{\circ} \mathrm{C}$, NIDA [18] slightly overestimates the failure load. The discrepancy between the Eurocode 3 [1] and the NIDA [18] estimates ranges from $-1.6 \%$ to $6.8 \%$.

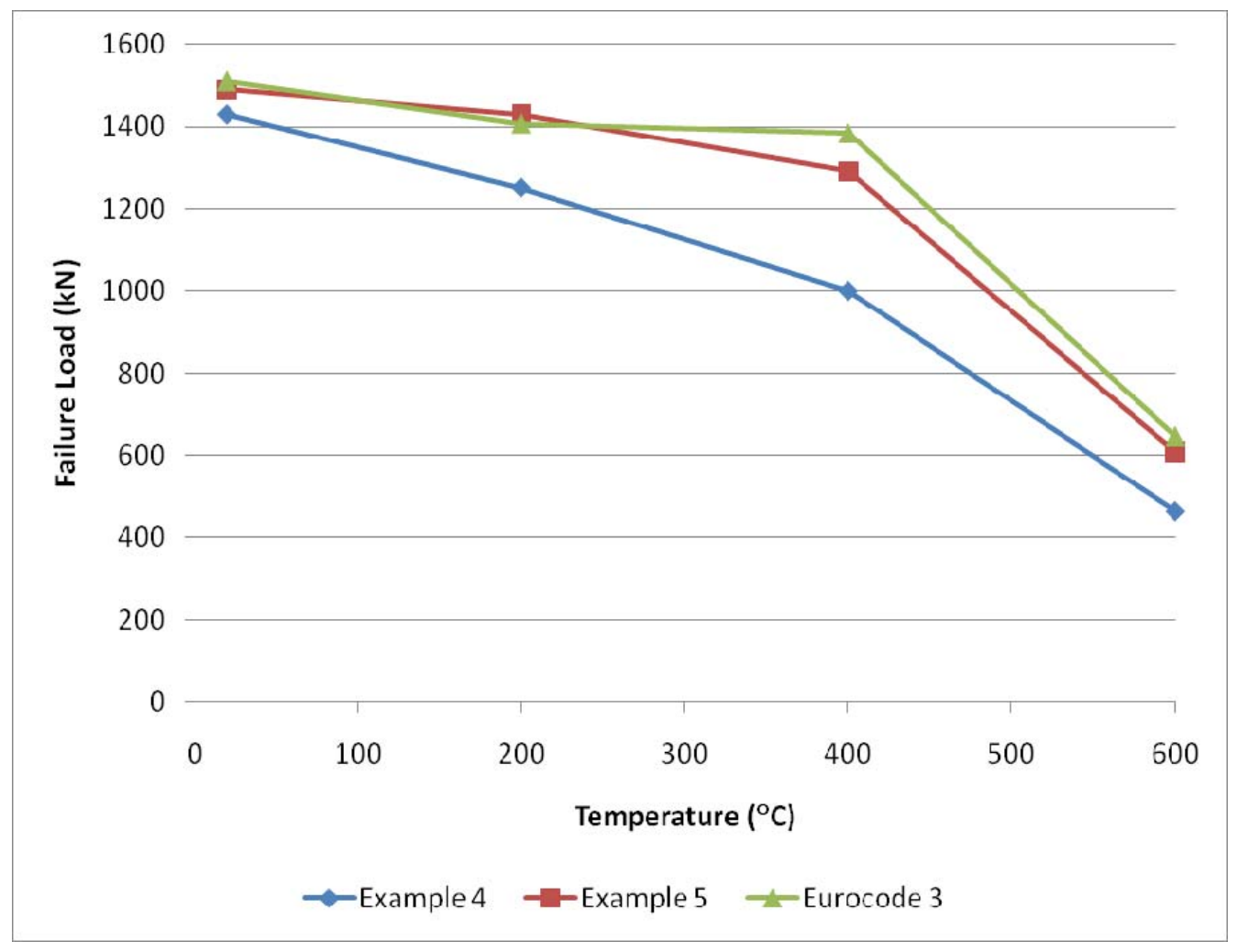

Figure 12. Comparison between NIDA and Eurocode 3 Results 


\section{CONCLUSIONS AND FUTURE WORKS}

Unlike the complicated finite element modelling of steel columns and framed structures at elevated temperatures which has been carried out extensively over the past few decades, this paper aims to develop a simplified approach on fire resistance design using computer program NIDA [18] with the design strength and Young's modulus of the steel replaced by those given in Eurocode 3 Part 1-2 [1]. The aim is to present a modelling approach that can be handled easily by practical engineers using commercially available second-order analysis and design programs. With proper design against fire resistance, a building can be robust that it is insensitive to collapse under localized fire. However, in a realistic fire analysis, the structure under fire condition should be under constant service load with increasing temperature. So, in future study, the analysis should be extended to deal with realistic fire condition by splitting the analysis into two sequences. In the first sequence, the load is applied incrementally at normal condition until the service load is reached; in the second sequence, the load is remained constant while the temperature is increased incrementally and in each temperature increment the thermal response along the member and the mechanical response of the materials in each element are adjusted accordingly. Therefore, the actual tensile membrane action at large deflections can be studied.

\section{REFERENCES}

[1] CEN, "Eurocode 3 Design of Steel Structures - Part 1-2: General Rules - Structural Fire Design, BS EN 1993-1-2”, British Standards Institution, London, 2005.

[2] CEN, "Eurocode 3 Design of Steel Structures - Part 1-1: General Rules and Rules for Buildings, BS EN 1993-1-1”, British Standards Institution, London, 2005.

[3] Franssen, J.M., Talamona, D., Kruppa, J. and Cajot, L.G., "Stability of Steel Columns in Case of Fire: Experimental Evaluation”, Journal of Structural Engineering, ASCE, 1998, Vol. 124, No. 2, pp. 158-163.

[4] Yang, K.C., Lee, H.H. and Chan, O., "Performance of Steel H columns Loaded under Uniform Temperature”, Journal of Constructional Steel Research, Elsevier, 2006, Vol. 62, No. 3, pp. 262-270.

[5] Yang, K.C. and Hsu, R., "Structural Behavior of Centrally Loaded Steel Columns at Elevated Temperature”, Journal of Constructional Steel Research, Elsevier, 2009, Vol. 65, No. 10-11, pp. 2062-2068.

[6] BSI, "Structural Use of Steelwork in Building - Part 8: Part 8: Code of Practice for Fire Resistant Design, BS5950-8”, British Standards Institution, London, 2003.

[7] AISC. "Specification for Structural Steel Buildings, ANSI/AISC 360-05", American Institution of Steel Construction, Chicago (IL), 2005.

[8] Janss, J., "Statistical Analysis of Fire Tests on Steel Beams and Columns to Eurocode 3, Part 1.2”, Journal of Constructional Steel Research, Elsevier, 1995, Vol. 33, No. 1, pp. 39-50.

[9] Janss, J. and Minne, R., "Buckling of Steel Columns in Fire Conditions”, Fire Safety Journal, Elsevier, 1982, Vol. 4, No. 4, pp. 227-235.

[10] Ali, F. and O’Connor, D., "Structural Performance of Rotationally Restrained Steel Columns in Fire”, Fire Safety Journal, Elsevier, 2001, Vol. 36, No. 7, pp. 679-691.

[11] Wang, Y.C. and Davies, J.M., “An Experimental Study of Non-sway Loaded and Rotationally Restrained Steel Column Assemblies under Fire Conditions: Analysis of Test Results and Design Calculations”, Journal of Constructional Steel Research, Elsevier, 2003, Vol. 59, No. 3, pp. 291-313.

[12] Tan, K.H., Toh, W.S., Huang, Z.F. and Phng, G.H., "Structural Responses of Restrained Steel Columns at Elevated Temperatures. Part 1: Experiments”, Engineering Structures, Elsevier, 2007, Vol. 29, No. 8, pp. 1641-1652. 
[13] Wald, F., “Simoes da Silva, L., Moore, D.B., Lennon, T., Chladna, M., Santiago, A., Benes, M. and Borges, L., "Experimental Behaviour of a Steel Structure under Natural Fire, Fire Safety Journal, Elsevier, 2006, Vol. 41, No. 7, pp. 509-522.

[14] Wang, Y.C., "An Analysis of the Global Structural Behaviour of the Cardington Steel-framed Building during the Two BRE Fire Tests”, Engineering Structures, Elsevier, 2000, Vol. 22, No. 5, pp. 401-412.

[15] Wang, Y.C., Moore, D.B., “Steel Frames in Fire: Analysis”, Engineering Structures, Elsevier, 1995, Vol. 17, No. 6, pp. 462-472.

[16] Chen, J. and Young, B., "Design of High Strength Steel Columns at Elevated Temperatures”, Journal of Constructional Steel Research, Elsevier, 2008, Vol. 64, No. 6, pp. 689-703.

[17] “ABAQUS Analysis User’s Manual, Version 6.5”, ABAQUS, Inc, 2004.

[18] NIDA, “Non-linear Integrated Design and Analysis User's Manual, NAF-NIDA series, Version 8”, Department of Civil and Structural Engineering, The Hong Kong Polytechnic University, Hong Kong, 2009. (http://www.nida-naf.com)

[19] Burgess, I.W., El-Rimawi, J.A. and Plank, R.J., "A Secant Stiffness Approach to the Fire Analysis of Steel Beams”, Journal of Constructional Steel Research, Elsevier, 1988, Vol. 11, No. 2, pp 105-120.

[20] Chan, S.L. and Zhou, Z.H., "Pointwise Equilibrating Polynomial Element for Nonlinear Analysis of Frames”, Journal of Structural Engineering, ASCE, 1994, Vol. 120, No. 6, pp. 1703-1717.

[21] Chan, S.L. and Zhou, Z.H., "Second-order Elastic Analysis of Frames Using Single Imperfect Element per Member”, Journal of Structural Engineering, ASCE, 1995, Vol. 121, No. 6, pp. 939-945.

[22] BD, “Code of Practice for Structural Use of Steel 2005”, Buildings Department, Hong Kong SAR Government, 2005. 